九州大学学術情報リポジトリ

Kyushu University Institutional Repository

\title{
Development of a solution model to correlate solubilities of inorganic compounds in water vapor under high temperatures and pressures
}

Shin, Hun Yong

Department of Chemical Engineering, Faculty of Engineering, Kyushu University

Matsumoto, Kota

Department of Chemical Engineering, Faculty of Engineering, Kyushu University

Higashi, Hidenori

Department of Chemical Engineering, Faculty of Engineering, Kyushu University

Iwai, Yoshio

Department of Chemical Engineering, Faculty of Engineering, Kyushu University

他

http://hdl. handle. net/2324/12527

出版情報：Journal of Supercritical Fluids. 21 (2)，pp.105-110，2001-10. Elsevier バージョン:

権利関係: (C) 2001 Elsevier Science B.V. All rights reserved. 
Manuscript for Journal of supercritical fluids

Revised manuscript ( jscf 00-71 ek)

Development of a solution model to correlate solublilties of inorganic compounds in water vapor under high temperatures and pressures

Hun Yong Shin, Kota Matsumoto, Hidenori Higashi, Yoshio Iwai*, Yasuhiko Arai Department of Chemical Engineering, Faculty of Engineering, Kyushu University, 6-10-1, Hakozaki, Higashi-ku, Fukuoka, 812-8581, Japan

E-mail : iwai@chem-eng.kyushu-u.ac.jp Fax : +81-92-642-3496

$\begin{array}{ll}\text { Text } & \text { p.1-6 } \\ \text { Table } & 1,2 \\ \text { Figure } & 1-7\end{array}$




\begin{abstract}
A solution model, based on the regular solution theory coupled with Flory-Huggins entropy term, was developed for the calculation of solubilities of inorganic compounds in water vapor under high temperatures and pressures. The solubilities of sodium chloride $(\mathrm{NaCl})$, potassium hydroxide $(\mathrm{KOH})$, sodium sulfate $\left(\mathrm{Na}_{2} \mathrm{SO}_{4}\right)$, lead oxide $(\mathrm{PbO})$, silicon oxide $\left(\mathrm{SiO}_{2}\right)$, lithium nitrate $\left(\mathrm{LiNO}_{3}\right)$, sodium nitrate $\left(\mathrm{NaNO}_{3}\right)$ and potassium nitrate $\left(\mathrm{KNO}_{3}\right)$ were correlated by optimizing internal energies and molar volumes of inorganic compounds which give their solubility parameters.
\end{abstract}

Keywords : solubility, water, salt, inorganic compound, regular solution theory

\title{
1. Introduction
}

The solubilities of inorganic salts at high temperature and pressure in water vapor are important in the field such as SCWO ( supercritical water oxidation) technology. SCWO is an emerging technology for the treatment of the organic wastes. The properties of water above its critical point (647K, 22.1MPa) bring about rapid and complete decomposition of such wastes. In the SCWO process, when organic compounds including halogen are decomposed, hydrogen halides cause remarkable corrosion of the reactor. In order to prevent the corrosion, alkalis are added as a neutralization reagent. As a result, inorganic salts such as $\mathrm{NaCl}$ and $\mathrm{Na}_{2} \mathrm{SO}_{4}$ precipitate and cause plugging of the reactor. For effective discharge of these inorganic salts from the reactor, their solubility data in water are very important to design the 
SCWO process [1]. In this study, therefore, a solution model was proposed to estimate the solubilities of inorganic salts and other inorganic compounds.

\section{Solutions model}

\subsection{Approximation of solubility}

The phase equilibria between solid and dense fluid phases can be approximated as the solid-liquid equilibria. Therefore, the solubility of a solid solute in a compressed fluid can be expressed by the following model which is derived from the regular solution theory and the athermal solution theory [2-3].

$$
\ln y_{2}=\frac{\Delta h_{2}^{m}}{R T}\left(\frac{T}{T_{2}^{m}}-1\right)-\frac{v_{2}}{R T}\left(\delta_{1}-\delta_{2}\right)^{2}-1+\frac{v_{2}}{v_{1}}-\ln \frac{v_{2}}{v_{1}}
$$

where subscripts 1 and 2 respectively denote water and solute and $\Delta h^{m}$ and $T^{m}$ indicate the heat of fusion and the melting point. They are listed in Table 1. Further, $v$ and $\delta$ represent the molar volume and the solubility parameter.

\subsection{Solublility parameter of water}

The solubility parameter of liquid water was evaluated by the following expression according to Sagara et al. [4].

$$
\delta_{1}=\frac{\sqrt{6 v_{1}^{S} \varepsilon_{11} N_{A}}}{v_{1}}
$$

where $v_{1}^{s}$ is the solid molar volume of water $\left(v_{1}^{s}=1.963 \times 10^{-5} \mathrm{~m}^{3} / \mathrm{mol}\right), \varepsilon_{11}$ is the pair potential energy, and $N_{A}$ is the Avogadro's number. The value of $\varepsilon_{11}$ was determined by using the approach proposed by Sagara et al. [4]. Namely, the solubility parameter given by 
Eq. (2) was fitted to the experimental solubility parameter:

$$
\delta_{1}=\sqrt{\left(\frac{\Delta h_{1}^{\text {vap }} / R T}{Z_{1}^{V}-Z_{1}^{V}}-1\right)\left(Z_{1}^{V} / Z_{1}^{L}\right) P_{1}^{s}}
$$

where $\Delta h_{1}^{\text {vap }}$ and $P_{1}^{s}$ denote the heat of vaporization and the saturated vapor pressure of water, respectively. Further, $Z_{1}^{V}$ and $Z_{1}^{L}$ are the compressibility factors of water in vapor and liquid phases, respectively.

The calculated result by Eq. (2) was fitted to the experimental value given by Eq. (3) at $T_{r}$ $=0.7$ to evaluate the value of $\varepsilon_{11} . T_{r}=0.7$ was selected by Sagara et al. [4] as a standard temperature to obtain a reliable parameter for wide range of temperature including near critical temperature. The calculated results of solubility parameters as a function of temperature and the value of $\varepsilon_{11}$ which is divided by the Boltzmann's constant $k$ are shown in Fig. 1. This figure shows the comparison of the calculated solubility parameters of water by Eq. (2) with the experimental data by Eq. (3). In the present solution model, the solubility parameters of water were obtained by Eq. (2) and the unknown variable, the pair potential energy, was determined using the experimental data by Eq. (2). Eq. (2) can give the solubility parameters of water as a function of molar volume at given temperature and pressure. In this work, therefore, Eq. (2) was extended to the vapor region. The molar volume of water vapor, $v_{1}$, was calculated by IAPWS-IF97 [5].

\subsection{Solubility parameters of inorganic compounds}

On the other hand, the solubility parameter of solute is given by the following equation [6]:

$$
\delta_{2}=\sqrt{\Delta u_{2} / v_{2}}
$$


where is $\Delta u_{2}$ the cohesive energy due to intermolecular potential energy.

\subsection{Molar volume of solid solute in dense fluid}

Iwai et al. [7] have empirically presented the following relation between the molar volume of solute $v_{2}$ and the density of supercritical fluid $\rho_{1}$ as

$$
\ln v_{2}=\alpha_{2} \ln \rho_{1}+\beta_{2}
$$

where $\Delta u_{2}$ in Eq.(4) and $\alpha_{2}, \beta_{2}$ in Eq.(5) are considered as adjustable parameters. As fewer number of parameters will be convenient for the industrial application, so $\alpha_{2}$ is set to a constant value.

\section{Results and Discussion}

The values of parameters fitted for inorganic salts and other inorganic compounds are listed in Table 2. The correlated results for the solubilities of $\mathrm{NaCl}, \mathrm{KOH}, \mathrm{SiO}_{2}$ and $\mathrm{NaNO}_{3}$ are shown in Figs. 2 - 5. The solubilities of $\mathrm{LiNO}_{3}, \mathrm{NaNO}_{3}$ and $\mathrm{KNO}_{3}$, which have the same anion, are compared at $748 \mathrm{~K}$ in Fig. $6 . \mathrm{LiNO}_{3}$ shows the highest solubility in water vapor among the inorganic compounds containing $\mathrm{NO}_{3}{ }^{-}$. Furthermore, the comparison of the solubility parameters was examined by the deviations of the solubility parameters of the inorganic compounds from that of water in Fig. 7. The difference between the solubility parameters of salts and that of water is related to the miscibility of salts in water. When the difference is smaller, the salts become more miscible in water. Fig 7 explains which salt is most miscible in water. These results are consistent with those in Fig.6. It will show the soundness of the present model. The smallest deviation of $\mathrm{LiNO}_{3}$ proves the highest solubility compared with the inorganic compounds containing $\mathrm{NO}_{3}{ }^{-}$such as $\mathrm{NaNO}_{3}$ and $\mathrm{KNO}_{3}$. 
Among the present systems, $\alpha_{2}$ can be treated as a constant $\left(\alpha_{2}=-1.0\right)$ while $\alpha_{2}=-1.34$ for the solubility correlation of several hydrocarbons in supercritical carbon dioxide [7]. The values of $\alpha_{2}$ are the same order of magnitude. Further, $\beta_{2}$ is found to be a constant for the given inorganic salts and other compounds. On the other hand, the cohesive energy $\Delta u_{2}$ in Eq.4 slightly depends on the temperature as shown in Table 2.

\section{Acknowledgements}

We gratefully acknowledge the financial support provided by "Research for the Future" Program (96P00401), The Japan Society for the Promotion of Science.

\section{References}

[1] M.M. DiPippo, K. Sako, J.W. Tester, Ternary phase equilibria for the sodium chloride-sodium sulfate-water system at 200 and 250 bar up to $400^{\circ} \mathrm{C}$, Fluid Phase Equilibria, 157 (1999) 229

[2] J.H. Hildebrand, R.L. Scott, Regular Solutions, Prentice-Hall, Inc., Englewood Cliffs, N.J., 1962.

[3] A. Kramer, G. Thodos, Adaptation of the Flory-Huggins theory for modeling supercritical solubilities of solid, Ind. Eng. Chem. Res., 27 (1988) 1506.

[4] H. Sagara, Y. Arai, S. Saito, Calculation of Henry’s constant of gases in hydrocarbon solvent by regular solution theory, J. Chem. Eng. Japan, 8 (1975) 93.

[5] W. Wagner, A. Kruse, Properties of Water and Steam, Springer, Tokyo, Japan, 1998 p. 7.

[6] A.F.M. Barton, Handbook of Solubility Parameters and Other Cohesion Parameters, CRC : Boca Raton Florida, (1983) p.8. 
[7] Y Iwai, Y. Koga, T. Fukuda, Y. Arai, Correlation of solubilities of high-boiling components in supercritical carbon dioxide using a solution model, J. Chem. Eng. Japan, 25 (1992) 757.

[8] M.W. Chase, Jr., C.A. Davies, J. R. Downey, Jr., D.J. Frurlp, R. A. McDonalde, A. N. Syverud, JANAF Thermochemical Tables Part I, Part II, American Chemical Society and the American Institute of Physics for the National Bureau of Standards, New York, Vol. 14, 1985, p.770, 1219, 1584, 1645, 1675.

[9] The Chemical Society of Japan, KAGAKU BINRAN KISOHEN II, Maruzen, Tokyo, Japan, 1993, p. II-245.

[10] J.F. Galobardes, D.R. Van Hare, L.B. Rogers, Solubility of sodium chloride in dry steam, J. Chem. Eng. Data, 26 (1981) 363.

[11] F.J. Armellini, J.W. Tester, Solubility of sodium chloride and sulfate in sub- and supercritical water vapor from $450-550^{\circ} \mathrm{C}$ and $100-250$ bar, Fluid Phase Equilibria, 84 (1993) 123.

[12] W.T. Wofford, P.C. Dell’Orco, E.F. Gloyna, Solubility of potassium hydroxide and potassium phosphate in supercritical water, J. Chem. Eng. Data, 40 (1995) 968.

[13] G.W. Morey, J.M. Hesselgesser, The solubility of some minerals in superheated steam at high pressures, Econ. Geol., 46 (1951) 821.

[14] C. Yokoyama, A. Iwabuchi, S. Takahashi, Solubility of PbO in supercritical water, Fluid Phase Equilibria, 82 (1993) 323.

[15] P. Dell'Orco, H. Eaton, T. Reynolds, S. Buelow, The solubility of 1:1 nitrate electrolytes in supercritical water, J. Supercritical Fluids, 8 (1995) 217. 
Table 1.

Physical properties of inorganic compounds

\begin{tabular}{cccc}
\hline $\begin{array}{c}\text { Inorganic } \\
\text { compound }\end{array}$ & $T^{m}(\mathrm{~K})$ & $\Delta h^{m}(\mathrm{~J} / \mathrm{mol})$ & Reference \\
\hline \hline $\mathrm{NaCl}$ & 1074 & 28158 & 8 \\
$\mathrm{KOH}$ & 679 & 8619 & 8 \\
$\mathrm{Na}_{2} \mathrm{SO}_{4}$ & 1157 & 23849 & 8 \\
$\mathrm{PbO}$ & 1159 & 25522 & 8 \\
$\mathrm{SiO}_{2}$ & 1696 & 7699 & 8 \\
$\mathrm{LiNO}_{3}$ & 527 & 25500 & 9 \\
$\mathrm{NaNO}_{3}$ & 583 & 16000 & 9 \\
$\mathrm{KNO}_{3}$ & 610 & 12000 & 9 \\
\hline
\end{tabular}


Table 2.

Parameters and AAD (Absolute Average error Deviation) of water(1) + inorganic compound(2) systems ( $\left.\alpha_{2}=-1.0\right)$.

\begin{tabular}{|c|c|c|c|c|c|}
\hline $\begin{array}{l}\text { Inorganic } \\
\text { compound } \\
\end{array}$ & $\beta_{2}$ & $T(\mathrm{~K})$ & $\begin{array}{c}\Delta u_{2} \times 10^{-4} \\
(\mathrm{~J} / \mathrm{mol})\end{array}$ & AAD (\%) & Reference \\
\hline \multirow{4}{*}{$\mathrm{NaCl}$} & \multirow{4}{*}{-2.62} & 673 & 12.62 & 6.9 & 10 \\
\hline & & 723 & 13.98 & 56.4 & 10,11 \\
\hline & & 773 & 14.06 & 22.2 & 10,11 \\
\hline & & 823 & 14.74 & 19.4 & 10,11 \\
\hline \multirow{3}{*}{$\mathrm{KOH}$} & \multirow{3}{*}{-3.55} & 723 & 10.53 & 6.5 & 12 \\
\hline & & 748 & 10.91 & 5.5 & 12 \\
\hline & & 773 & 11.13 & 6.5 & 12 \\
\hline $\mathrm{Na}_{2} \mathrm{SO}_{4}$ & -5.74 & 773 & 9.26 & 20.8 & 13 \\
\hline \multirow{3}{*}{$\mathrm{PbO}$} & \multirow{3}{*}{-5.99} & 673 & 6.64 & 9.6 & 14 \\
\hline & & 723 & 6.97 & 3.1 & 14 \\
\hline & & 773 & 7.41 & 7.2 & 14 \\
\hline \multirow{2}{*}{$\mathrm{SiO}_{2}$} & \multirow{2}{*}{-5.74} & 673 & 7.60 & 6.9 & 14 \\
\hline & & 773 & 7.75 & 6.7 & 14 \\
\hline $\mathrm{LiNO}_{3}$ & -2.69 & 748 & 15.32 & 3.7 & 15 \\
\hline \multirow{4}{*}{$\mathrm{NaNO}_{3}$} & \multirow{4}{*}{-3.35} & 723 & 11.14 & 0.8 & 15 \\
\hline & & 748 & 11.49 & 2.5 & 15 \\
\hline & & 773 & 11.70 & 9.6 & 15 \\
\hline & & 798 & 12.09 & 6.4 & 15 \\
\hline $\mathrm{KNO}_{3}$ & -3.49 & 748 & 11.12 & 4.8 & 15 \\
\hline
\end{tabular}




\section{Figure Captions}

Fig. 1. Solubility parameter of water.

Fig. 2. Solubilities of $\mathrm{NaCl}$ in water vapor.

Fig. 3. Solubilities of $\mathrm{KOH}$ in water vapor.

Fig. 4. Solubilities of $\mathrm{SiO}_{2}$ in water vapor.

Fig. 5. Solubilities of $\mathrm{NaNO}_{3}$ in water vapor.

Fig. 6. Comparison of solubilites of $\mathrm{KNO}_{3}, \mathrm{NaNO}_{3}$ and $\mathrm{LiNO}_{3}$ in water vapor at $748 \mathrm{~K}$.

Fig. 7. Comparison of solubility parameters of water, $\mathrm{KNO}_{3}, \mathrm{NaNO}_{3}$ and $\mathrm{LiNO}_{3}$ at $748 \mathrm{~K}$. 


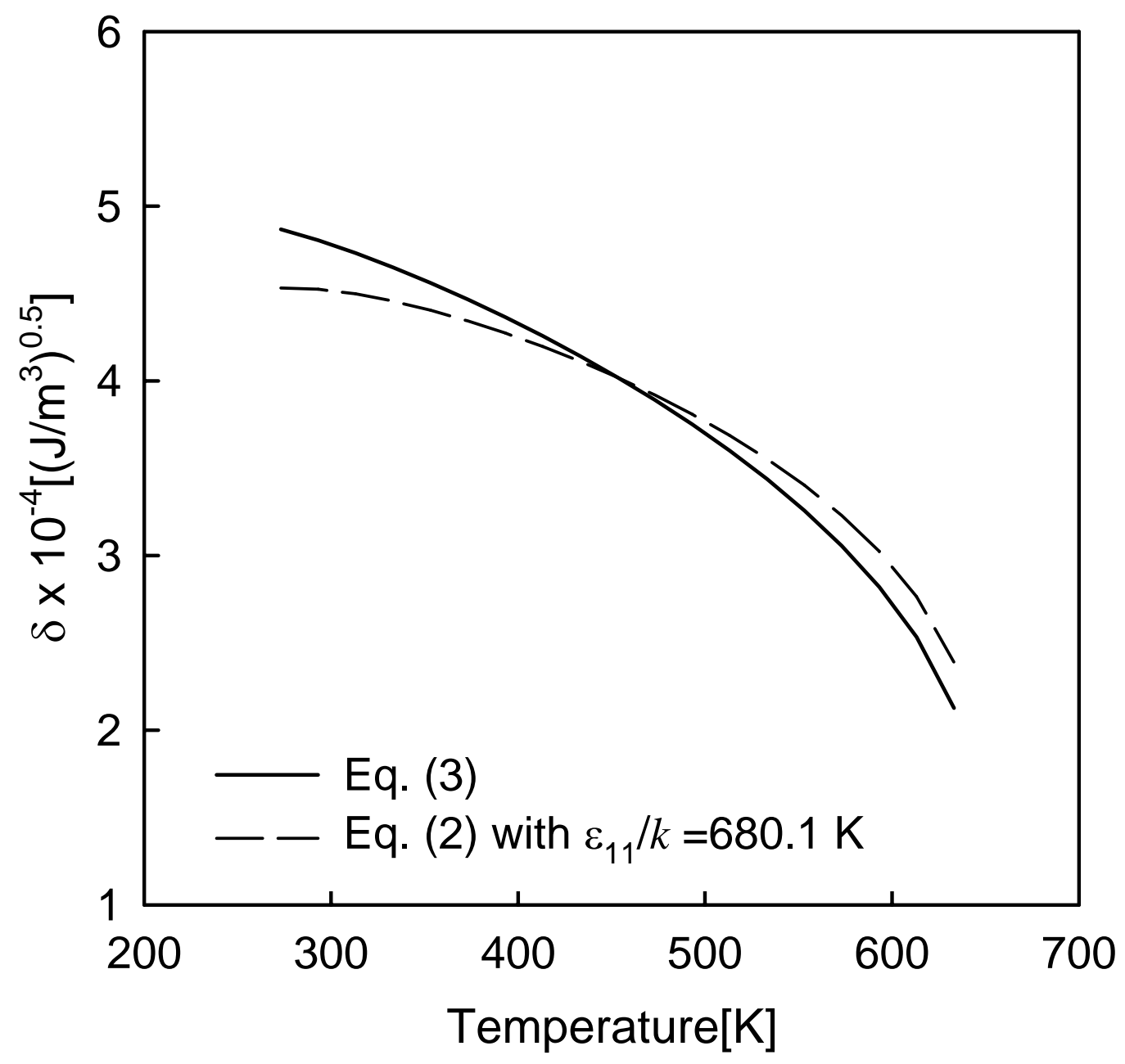

Fig. 1 

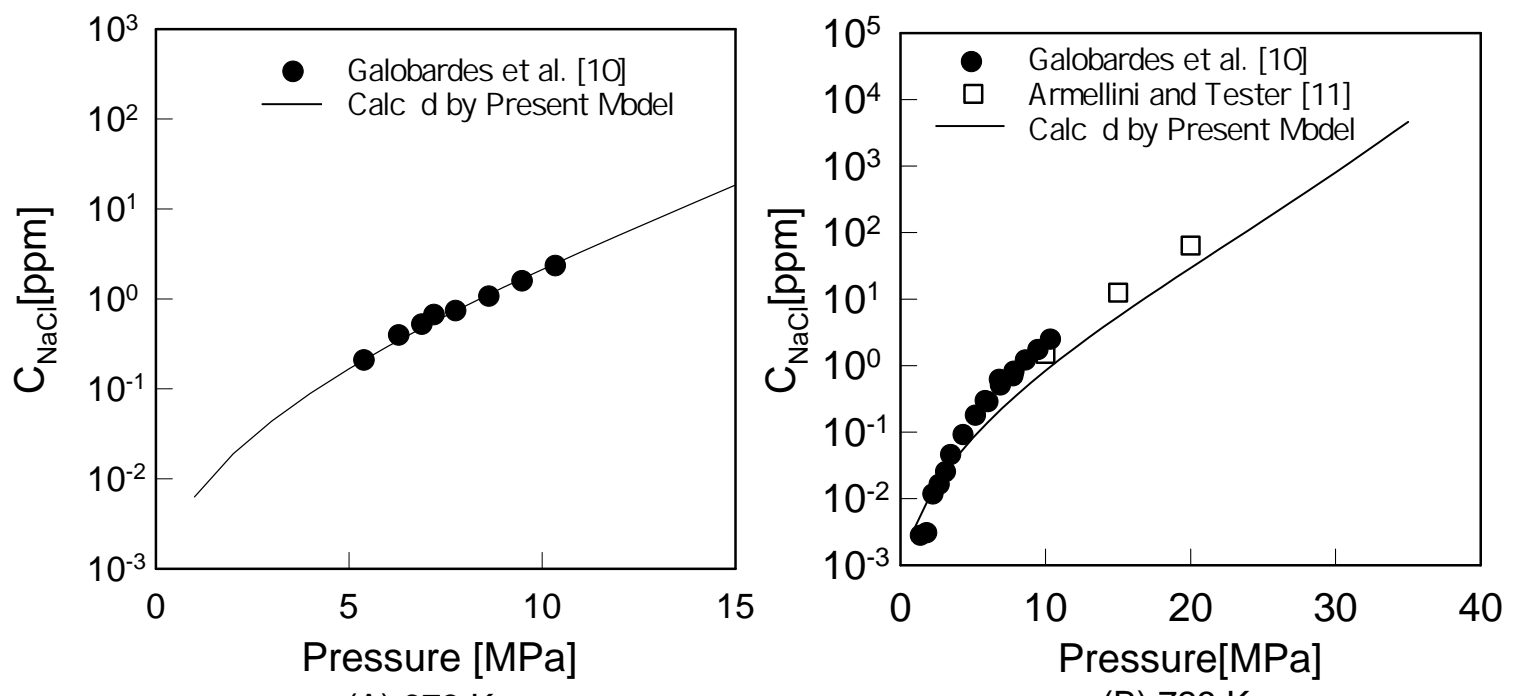

(A) $673 \mathrm{~K}$

(B) $723 \mathrm{~K}$
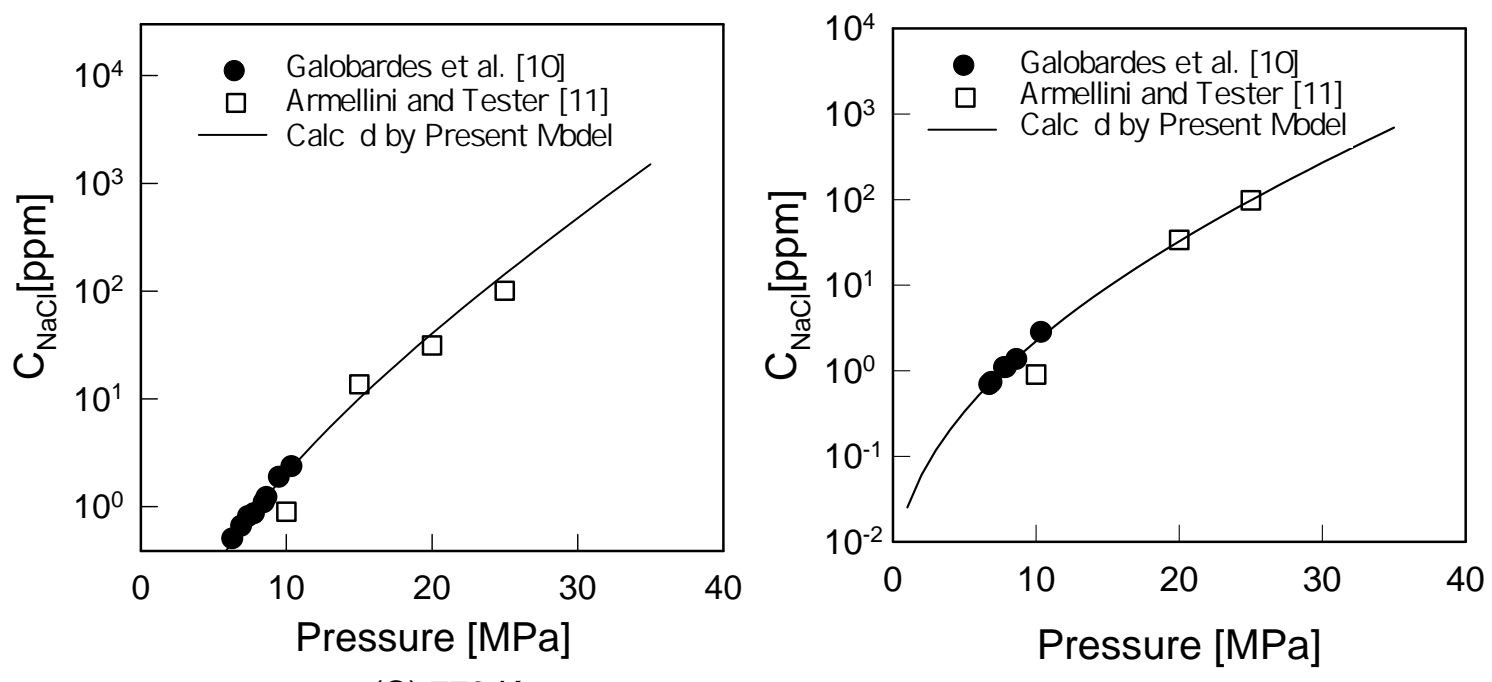

(C) $773 \mathrm{~K}$

(D) $823 \mathrm{~K}$

Fig. 2 


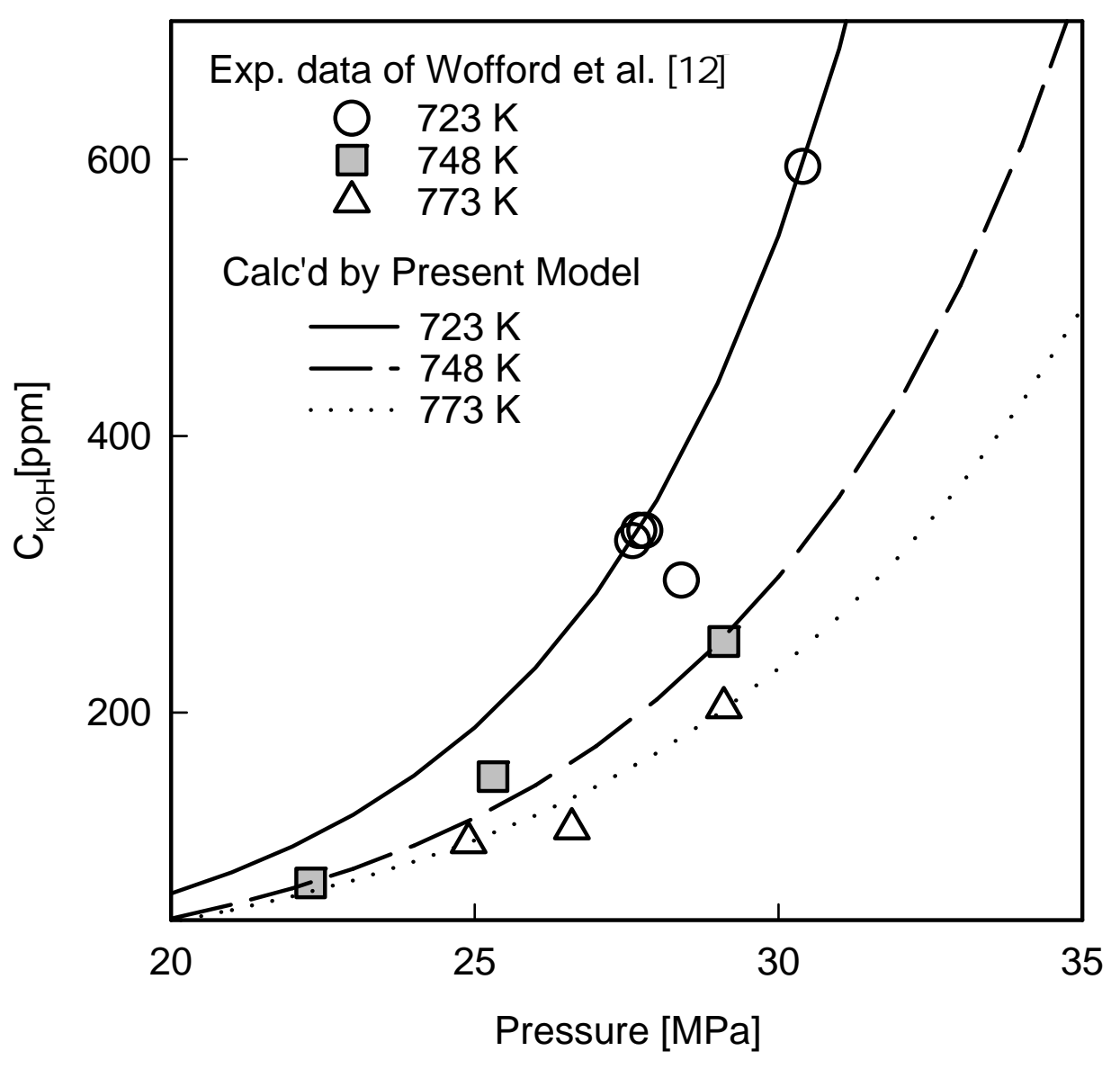

Fig. 3. 


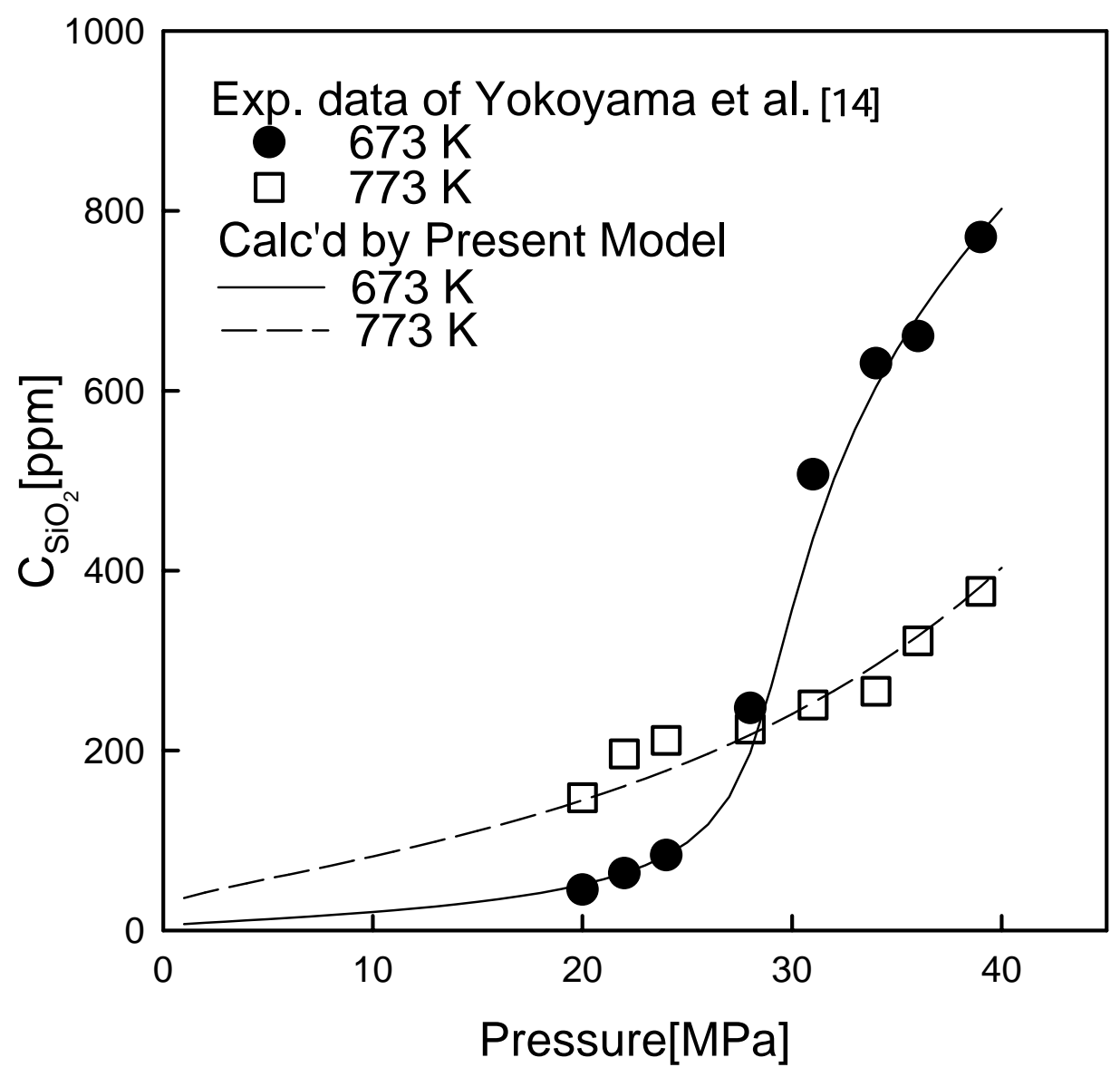

Fig . 4. 


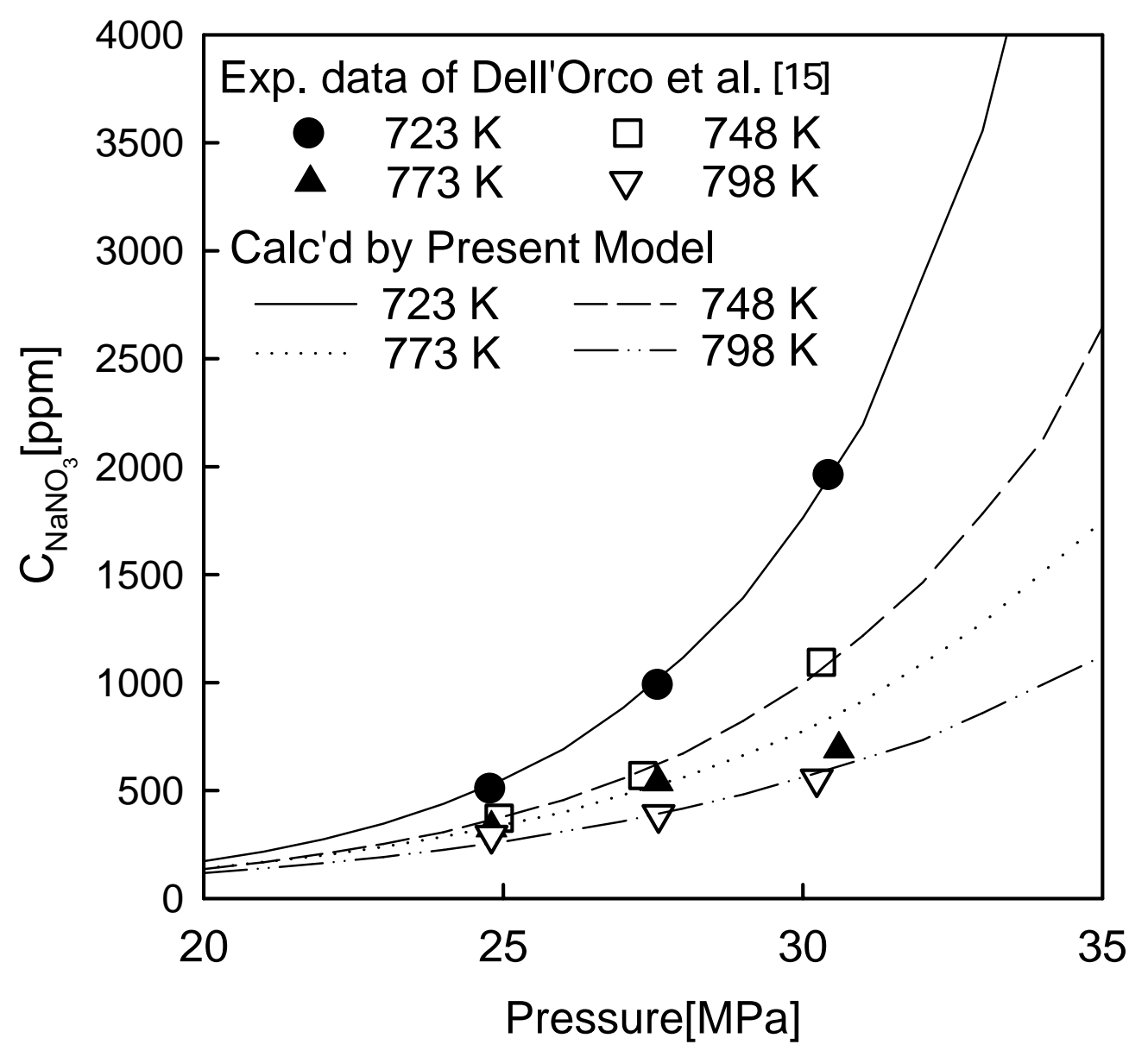

Fig . 5 . 


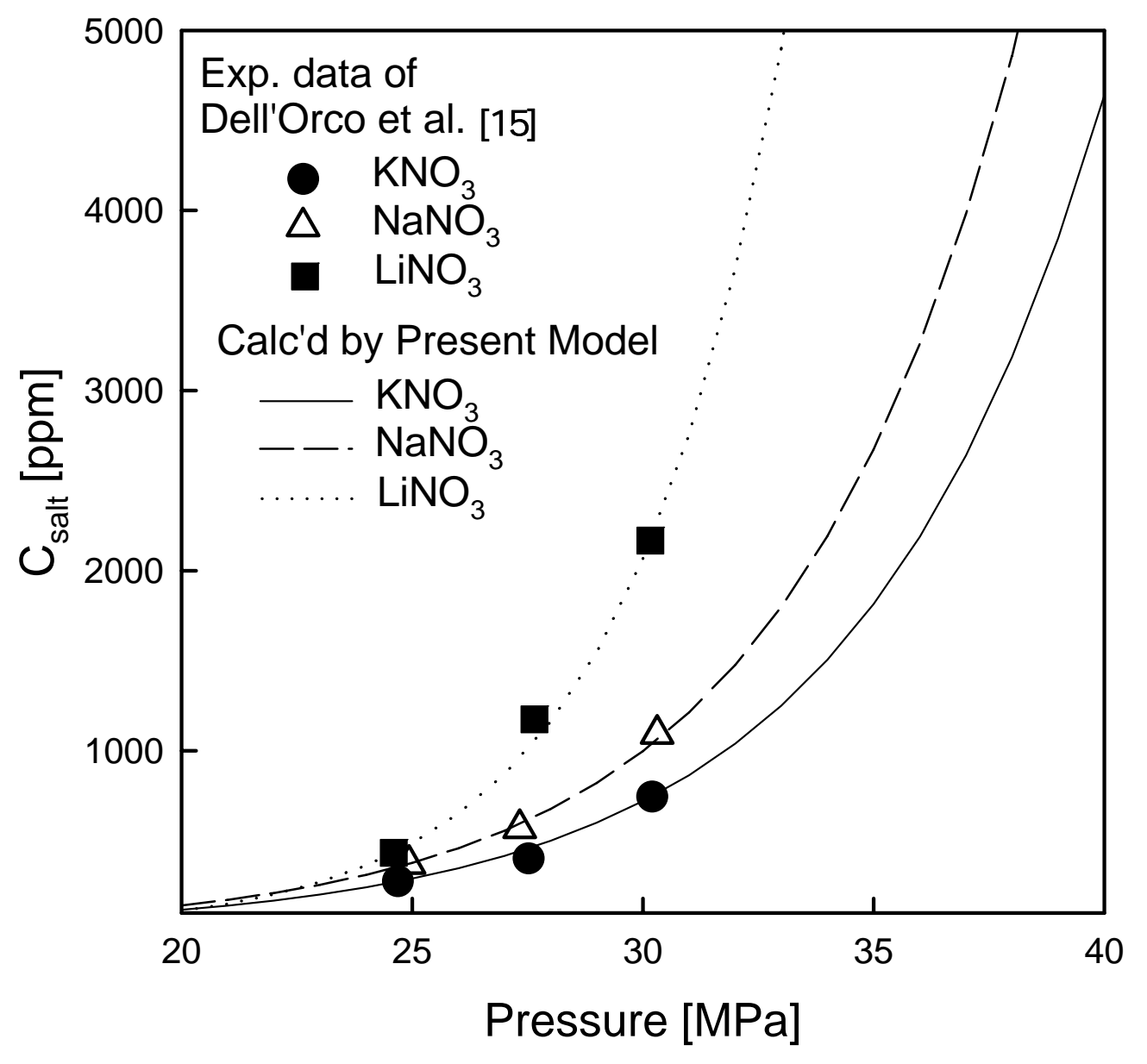

Fig . 6 . 


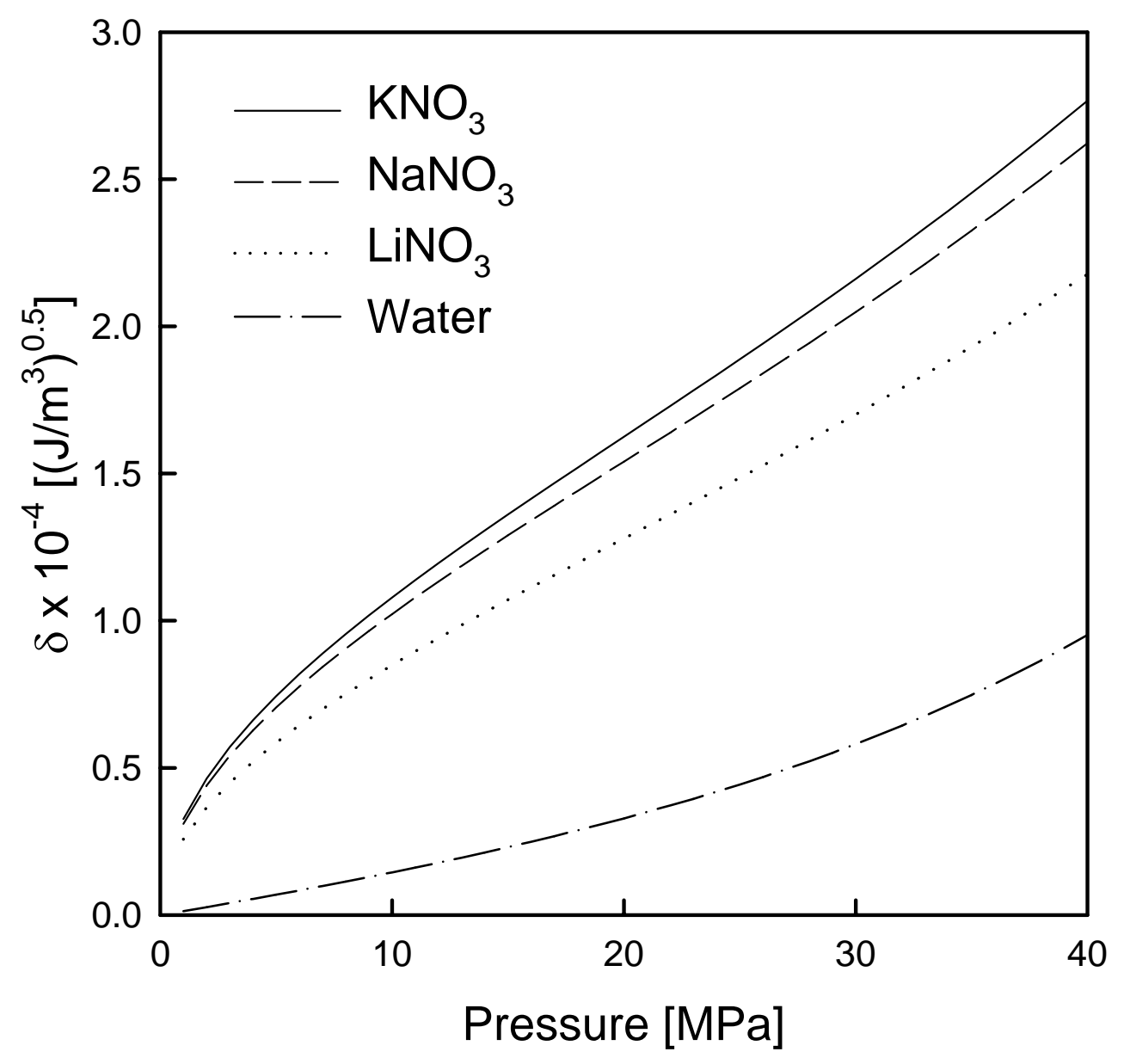

Fig . 7 